\begin{tabular}{|c|c|}
\hline Title & Dependence of premixed low-temperature diesel combustion on fuel ignitability and volatility \\
\hline Author(s) & Li, Tie; Moriwaki, Riichi; Ogawa, Hideyuki; Kakizaki, Ryuta; Murase, Masato \\
\hline Citation & $\begin{array}{l}\text { International Journal of Engine Research, 13(1), } 1427 \\
\text { https://doi.org/10.1177/1468087411422852 }\end{array}$ \\
\hline Issue Date & 2012-02 \\
\hline Doc URL & http:/hdl.handle.net/2115/51754 \\
\hline Rights & $\begin{array}{l}\text { The final, definitive version of this article has been published in the Journal, International Journal of Engine Research, } \\
\text { 13(1), } 2012 \text { of publication, @ Institution of Mechanical Engineers, } 2012 \text { by SA GE Publications L td at the International } \\
\text { Journal of Engine Research page: http://\$er.sagepub.com/on SA GE Journals S Online: http://online.sagepub.com/ }\end{array}$ \\
\hline Type & article (author version) \\
\hline File Information & IJER13-1_14-27.pdf \\
\hline
\end{tabular}

Instructions for use 
Title:

Dependence of Premixed Low-Temperature Diesel Combustion on Fuel Ignitability and Volatility

Authors and affiliations:

Tie Li $^{1}$, Riichi Moriwaki ${ }^{1}$, Hideyuki Ogawa ${ }^{1}$, Ryuta Kakizaki ${ }^{2}$, Masato Murase ${ }^{3}$

${ }^{1}$ Division of Energy and Environmental Systems, Faculty of Engineering, Hokkaido University

${ }^{2}$ Mitsubishi Motor Corporation

${ }^{3}$ JOMO Technical Research Centre

Corresponding address:

Tie Li

Division of Energy and Environmental Systems,

Graduate School of Engineering, Hokkaido University

N13 W8, Kita-ku, Sapporo 060-8628, Japan

Tel: +80-11-706-6384, Fax: +81-11-706-6384

Email: litie@eng.hokudai.ac.jp 


\title{
Dependence of Premixed Low-Temperature Diesel Combustion on Fuel Ignitability and Volatility
}

\author{
Tie $\mathbf{L i}^{1}$, Riichi Moriwaki ${ }^{1}$, Hideyuki Ogawa ${ }^{1}$, Ryuta Kakizaki ${ }^{2}$, Masato Murase ${ }^{3}$ \\ ${ }^{1}$ Division of Energy and Environmental Systems, Faculty of Engineering, Hokkaido University \\ ${ }^{2}$ Mitsubishi Motor Corporation \\ ${ }^{3}$ JOMO Technical Research Centre
}

\begin{abstract}
:
A comprehensive study of fuel property effects in internal combustion engines is required to enable fuel diversification as well as applications to advanced engines being developed for operation with a variety of combustion modes. The objective of this paper is to investigate the effects of fuel ignitability and volatility over a wide range on premixed low-temperature combustion (LTC) modes in diesel engines. Twenty three fuels were prepared from commercial gasoline, kerosene, and diesel as baseline fuels and with the addition of additives, to generate a cetane number $(\mathrm{CN})$ range from 11 to 75 . Experiments with a single cylinder diesel engine operated in moderately-advanced-injection LTC modes were conducted to evaluate these fuels. The combustion phasing is demonstrated to be a good indicator to estimate the in-cylinder peak pressure, exhaust gas emissions, and thermal efficiency in the LTC mode. Fuel ignitability affects the combustion phasing by changing the ignition delay. The predicted cetane number (PCN) based on fuel molecular structure analysis can be fitted to the ignition delays with a higher coefficient of determination than $\mathrm{CN}$, suggesting a good potential as a fuel ignitability measure over a wide range. The stable operating load range in the smokeless LTC mode depends more on the actual ignition delay or PCN rather than $\mathrm{CN}$. With fixed injection timing and intake oxygen concentration, $\mathrm{O}_{2 \text { in }}$, only when $\mathrm{PCN}<40$, the load range can be expanded significantly to higher loads. With holding the combustion phasing at TDC and varying $\mathrm{O}_{2 \text { in }}$, the NOx and smoke emissions become limitations of the load expansion for some fuels. The effects of fuel volatility on the characteristics of LTC are small compared to ignitability. Finally, the operational injection timing range and robustness of the LTC to fuel ignitability are examined, showing that the advantageous ignitability range becomes narrower with fuel ignitability decreasing.
\end{abstract}

Keywords: Fuels; Ignitability; volatility; Low temperature combustion (LTC); Diesel engines; Cetane number 


\section{INTRODUCTION}

Internal combustion engines (ICEs) compatible with multiple fuels of various properties are required to enable the fuel diversification necessitated by the limited reserves and rising prices of crude oil. Further, the development of multi-fuel-compatible engines can mitigate the requirements of fuel properties, increase the flexibility of fuel design, and reduce the energy consumption in oil refineries. While advanced electronically-controlled technologies could make such engines possible, these engines must meet the steadily more stringent requirements for higher fuel efficiencies and lower exhaust emissions while keeping the engine systems cost-efficient.

Diesel engines have the highest thermal efficiency among ICEs and are compatible with a wider range of fuels than gasoline engines. For instance, recent research has shown that gasoline can be simply converted to work in diesel engines with higher efficiency than in spark ignition engines [1-4]. However, due to the trade-off between soot and nitrogen oxides (NOx) from jet-mixing-controlled diesel combustion [5], it appears unlikely that conventional diesel engines can meet the increasingly stringent emission regulations coming into force in most industrialized countries without fairly expensive after-treatment systems [6-7], despite the significant reductions of engine-out emissions with advanced technologies including elevated injection pressure, sophistically-controlled injection strategy, cooled exhaust gas recirculation (EGR), and variable-geometry turbochargers. Nevertheless, to maintain the functioning of exhaust aftertreatment devices and fuel economy in relation to vehicle running cost, further reductions in engine-out emissions through improved combustion technologies are urgently required.

Premixed compression-ignition low-temperature combustion (LTC) engines can deliver both high efficiencies and ultra-low NOx and soot emissions [7-8]. Regarding diesel LTC, due to the low volatility of diesel fuels, most research is focused on direct injection strategies with either very-early injections for a lean mixture [9-11] or moderately-advanced (or retarded) injections with large quantities of cooled EGR [12-21]. In the very-early injection strategies, specially designed injector or injection strategies are necessary to avoid oil dilution by liquid spray impinging upon the cylinder walls. In addition to increased engine cost, however, engine performance would suffer with the specially designed systems when switched from LTC to conventional combustion at higher loads, since these strategies are limited to partial load operations.

Fuel injection systems for conventional diesel combustion can be readily utilized for moderately-advanced injections without concerns about cylinder wall wetting by spray, but large quantities of cooled EGR are generally necessary to realize LTC. As both ignition delay and combustion temperature are commonly changed with EGR, fuel-air mixing is believed to play important roles in ultra-high EGR LTC, although with sufficiently-lowered temperature, in principle, non-sooting combustion should be obtained regardless of fuel-air mixing [13]. Recent ex- 
periments demonstrated that as long as combustion temperature is sufficiently low, non-sooting LTC can be realized even with insufficient fuel-air mixing, but this is at the expense of dramatic increases in unburned hydrocarbons (UHC) and carbon monoxide (CO) emissions and unacceptable deterioration in fuel efficiency [22-24]. These results suggest that while lowered temperature is necessary for LTC, a promotion of fuel-air mixing at relatively high intake oxygen concentrations is extremely important for clean and highly-efficient combustion especially at higher loads.

While elevated injection pressures and enhanced swirl ratios can promote air-fuel mixing, sufficient premixing time between end of injection and ignition is necessary for non-sooting, efficient LTC. Lower cetane number (CN) can lead to longer ignition delays and premixing times, and reductions in compression ratios as well as increases in EGR can promote the effect of CN on premixing time [23-27]. As described in ASTM D613, CN is measured with a cooperative fuel research (CFR) engine under specific conditions similar to conventional diesel combustion. However, in diesel LTC with very long ignition delays, the ignition processes could be different from those in conventional diesel combustion as the reaction kinetics including low temperature oxidation can play more significant roles in ignition processes of LTC. Therefore, there is a necessity to examine the CN effects in the premixed LTC mode of diesel engines. Further, while commercial fuels for current diesel engines have CNs ranging from 40 to 57 , it is quite possible that fuels of lower ignitability will be considered for use in diesel engines to meet the requirements of higher thermal efficiencies, fuel diversification, and lower production cost for refineries in the future, like has been reported in references [1-4]. To elucidate this, more extensive investigations of the effects of fuel ignitability over a wider range on diesel engines operated in a wide range of combustion modes would be essential.

This study focuses on the effects of fuel property on the characteristics of diesel engines operated in the moderately-advanced-injection LTC mode over a CN range from 11 to 75 as well as with varying physical fuel properties including volatility and viscosity, and the objective is to provide essential information for future engine designs considering multi-combustion-mode operations and fuel diversification. Firstly, the effects of $\mathrm{CN}$ and the predicted cetane number (PCN) obtained by fuel molecular structure analysis on ignition delay and combustion are evaluated. Next, the correlation between the ignition delay and combustion phasing (CA50) is clarified, and the effects of CA50 on the characteristics of cylinder peak pressure, exhaust emissions, and thermal efficiency are presented. Moreover, the effects of fuel ignitability on the smooth operating load range of LTC are elucidated, and the effects of fuel volatility are discussed. Finally, operational injection timing range and robustness of the premixed LTC versus fuel ignitability are examined. 


\section{EXPERIMENTAL}

\subsection{Test engine and operating conditions}

Shown in Tables $1 \& 2$ are the specifications of test engine and operating conditions. Experiments were conducted on a single cylinder, naturally-aspirated, four-stroke, one liter, common-rail direct-injection diesel engine with a rated power of $11.8 \mathrm{~kW}$ at $2200 \mathrm{rpm}$. Several experiments on LTC in previous reports have also been conducted with this engine [19-26]. The injection pressure, $P_{i n j}$ was set at $60 \mathrm{MPa}$, engine speed at $1320 \mathrm{rpm}$, coolant temperature at $80^{\circ} \mathrm{C}$, temperature of the intake mixture including the cooled EGR gas around $30{ }^{\circ} \mathrm{C}$, and the swirl and compression ratios at 2.2 and 16 , respectively. The injection quantity was initially set so that the indicated mean effective pressure (IMEP) was kept at 0.3 MPa to evaluate the effects of the test fuels on the characteristics of the ignition, combustion, exhaust emissions, and thermal efficiency, and it was changed as necessary in the experiments evaluating the fuel effects on the operational load range. To achieve premixed LTC and isolate the effects of fuel property on the LTC, injection timing, $t_{i n j}$ was fixed at $30{ }^{\circ} \mathrm{CA}$ BTDC (crank angle degree before top dead centre), and intake oxygen concentration, $\mathrm{O}_{2 \mathrm{in}}$, which was monitored with a paramagnetic-type oxygen tester (POT-101: SHIMADZU), was held constant at $14 \%$ with controlling the EGR rate by gate valves. In the experiments with expansion of the operational load range of the LTC, a strategy of dynamically controlled injection timing for constant CA50 at TDC (top dead centre) were employed, and three intake oxygen concentrations: $10 \%, 14 \%$, and $16 \%$ were used. In evaluation of robustness of the LTC versus fuel ignitability, injection timing was swept in $3^{\circ} \mathrm{CA}$ increments from the stable operating limit to $30^{\circ} \mathrm{CA}$ BTDC that is the advanced limit to avoid the cylinder liner wetting owing to spray impingements. It should be mentioned that all the data were taken in the smokeless LTC mode, except for those in evaluation of robustness of the LTC versus fuel ignitability where some smoke emissions were exhausted for some injection timings.

\subsection{Test fuels}

Table 3 shows the properties of the test fuels. Twenty-three fuels were prepared from commercial gasoline (GS0), kerosene (KE0), diesel fuel (DF0), and primary reference fuels (PRF) as baseline fuels, and the fuels were used with and without additives to generate a $\mathrm{CN}$ range from 11 to 75 . The CNs above 30 were measured with a CFR engine following the procedure in ASTM D613. The other CNs, due to the unusually-low values, were achieved via blending with high $\mathrm{CN}$ fuels, measuring the $\mathrm{CNs}$ of the blends following standard procedures, and calculating the CNs based on the volume fractions of the blends. High reliability of the blending method has been 
demonstrated in reference [28].

Another fuel ignitability measure, PCN, obtained from the fuel molecular structure analysis using proton nuclear magnetic resonance $\left({ }^{1} \mathrm{H}-\mathrm{NMR}\right)$ spectroscopy is also evaluated in this study. Figure 1 shows the assignment and examples of hydrogen types on the ${ }^{1} \mathrm{H}$ - NMR spectra. Detailed information about PCN can be found in reference [28], here a brief description is given as follows. Firstly, 75 sample fuels with various ignitabilities over a wide range were prepared, and the CNs were measured with a CFR engine following the standard test procedure ASTM D613. Next, the molecular structure information of each sample fuel was obtained by the ${ }^{1} \mathrm{H}-\mathrm{NMR}$ spectroscopy. Finally, a model for PCN was obtained by multiple regression analysis with the measured CNs and molecular structure information of 75 sample fuels. It is given by

$$
\begin{aligned}
\mathrm{PCN}= & -1.277\left[\mathrm{H}_{\mathrm{a}}\right]+0.031\left[\mathrm{H}_{\mathrm{a}}\right]^{2}-4.092\left[\mathrm{H}_{\mathrm{o}}\right]-0.405\left[\mathrm{H}_{\mathrm{o}}\right]^{2} \\
& +0.055\left[\mathrm{H}_{\alpha}\right]+0.007\left[\mathrm{H}_{\alpha}\right]^{2}+1.063\left[\mathrm{H}_{\beta}\right]+0.002\left[\mathrm{H}_{\beta}\right]^{2} \\
& -0.648\left[\mathrm{H}_{\gamma}\right]+0.008\left[\mathrm{H}_{\gamma}\right]^{2}
\end{aligned}
$$

where $\left[\mathrm{H}_{\mathrm{a}}\right],\left[\mathrm{H}_{\mathrm{o}}\right],\left[\mathrm{H}_{\alpha}\right],\left[\mathrm{H}_{\beta}\right]$, and $\left[\mathrm{H}_{\gamma}\right]$ are the area percentages of different hydrogen types on the ${ }^{1} \mathrm{H}-\mathrm{NMR}$ spectra.

Plotted in Fig. 2 is the correlation between PCN and CN. Note that the fuels here were not included in the fuels used in developing Eq. (1), and the PCNs are calculated using Eq. (1) with the information of fuel molecular structure obtained from the ${ }^{1} \mathrm{H}$ - NMR spectra. In general, there are good correlations between PCN and CN, except for fuels with $\mathrm{CN}$ or PCN below 40 and fuels: DF3, DF4, and DF5. In the measurement of $\mathrm{CN}$, the compression ratio of the CFR engine is adjusted to meet a specified ignition delay $\left(2.407 \mathrm{~ms}\right.$ or $13^{\circ} \mathrm{CA}$ at $\left.900 \mathrm{rpm}\right)$, and the resulting $\mathrm{CN}$ is calculated by determining which mixture of cetane (hexadecane) and iso-cetane $(2,2,4,4,6,8$, 8-heptamethylnonane) will result in the same ignition delay. At $\mathrm{CN}$ below 40 , a very high compression ratio is necessary to meet the above condition, and it becomes difficult to discriminate the difference of fuel ignitability. Since PCN, although Eq. (1) is obtained by regression analysis with measured $\mathrm{CN}$ of sample fuels, does contain information of fuel molecular structure, it can reflect the fuel ignitability even at the very low ignitability range as will be shown in RESULTS AND DISCUSSION section.

As shown in Fig. 1, the analysis of fuel molecular structure using the ${ }^{1} \mathrm{H}-\mathrm{NMR}$ spectroscopy to deduce PCN cannot discriminate whether $\mathrm{H}_{\beta}$ sited in straight or cyclic alkanes. In addition, the effect of oxygen in oxygenate fuels is not identified by the ${ }^{1} \mathrm{H}$ - NMR spectroscopy used in the present study. Therefore, when the fuel contains significant amount of naphthenes or oxygenate components (ex. ETBE in DF4 and DF5 in this study), PCN may give an inaccurate measure for fuel ignitability. This issue should be addressed in the future work. 


\subsection{Analysis of indicator diagrams and exhaust gas emissions}

The in-cylinder pressure was measured by a water-cooled piezoelectric pressure transducer (6061B: KISTLER), and data of 90 cycles were sampled and averaged for the indicator analysis. The rate of heat release (ROHR) was calculated from the pressure data following a procedure similar to that in reference [29]. The ROHR was integrated from $30^{\circ} \mathrm{CA}$ BTDC to just prior to exhaust valve opening to obtain the cumulative apparent heat release, which was normalized by the maximum value. The ignition timing and combustion phasing are defined as the crank angles of 10\% (CA10) and 50\% (CA50) of the normalized cumulative heat release, respectively.

Exhaust gas was sampled about $1500 \mathrm{~mm}$ downstream from the engine exhaust valve, and was analyzed with an automotive exhaust gas analyzer (MEXA-9100DEGR: HORIBA) including a non-dispersive infrared absorption method for $\mathrm{CO}$, chemical luminescence detector for NOx, and heated flame ionization detector for UHC. The smoke concentration, which is a good estimate of soot or insoluble fractions in diesel particulate emissions, was measured with a Bosch-type smoke meter (DSM-20AN: ZEXEL).

A buffering chamber was set at $380 \mathrm{~mm}$ downstream from the engine exhaust valve to minimize the measuring uncertainty due to pulsing effects of the exhaust gases. Averages of several measurements are plotted in the figures and error bars are not shown to enable identification of the effects of different fuels more clearly. Moreover, prior to each new experiment, the engine was operated at conventional diesel combustion conditions without EGR from partial to full loads for 40 minutes to prevent the uncertainties associated with engine conditions from affecting the repeatability.

\section{RESULTS AND DISCUSSION}

\subsection{Effects of fuel ignitability on ignition delay and combustion}

Figure 3 shows the ignition delay as a function of $\mathrm{CN}$ and PCN. Here all the fuel injections are complete between -18.5 and $-19.5{ }^{\circ} \mathrm{CA}$ ATDC (data not shown), and even with GTL, which ignites at the earliest timing, there are still about $6{ }^{\circ} \mathrm{CA}$ premixing time after the end of injection. The solid line in each figure represents the best fitting approximation to the experimental data. While the ignition delay increases with $\mathrm{CN}$ decreasing as expected, neither exponential nor power function relations, which had been used in equations to predict ignition delays including CN [30-32], can be made to fit the data with coefficients of determination $\left(\mathrm{R}^{2}\right)$ above 0.8 . Instead, a piecewise linear $\mathrm{CN}$ dependent approximation (dashed line) appears to work better: with $\mathrm{CN}$ decreasing, the ignition delay increases linearly at three distinctly different gradients. At $40<\mathrm{CN}<60$, the ignition delay increases moderate- 
ly; and at $\mathrm{CN}<40$, it increases very steeply and shows large changes with small variations in CN. Compared to CN, the ignition delays show a closer correlation with $\mathrm{PCN}$ especially at $\mathrm{PCN}<40$. A polynomial approximation fits the data with $\mathrm{R}^{2}$ up to 0.9326 , and both exponential $\left(\mathrm{y}=39.073 \mathrm{e}^{-0.009 \mathrm{x}}\right)$ and power function $\left(\mathrm{y}=134.23 \mathrm{x}^{-0.44}\right)$ fittings can also give $\mathrm{R}^{2}$ above 0.9 .

Here the weaker correlation between the ignition delay and $\mathrm{CN}$ can be attributed to the large fluctuations especially at $\mathrm{CN}<40$, and several factors may be suggested to contribute to the large fluctuations. First, in the $\mathrm{CN}$ measurements, the compression ratio of the CFR engine is varied to meet a specific ignition delay in the conventional combustion mode where mixture formation processes may also affect the ignition strongly for all test fuels. In the LTC mode, however, early fuel injections are conducted in low oxygen and low temperature ambient environments to obtain much longer ignition delays, and the low temperature heat release (LTHR) may play a more significant role in the ignition processes than in the conventional diesel combustion. The LTHR is closely related to the fuel molecular structure [33]. Therefore, PCN shows good correlation with the ignition delay, while uncertainties increase when using $\mathrm{CN}$ as a measure for fuel ignitability in the premixed LTC mode. Moreover, here although all the parameters influencing ignition delays, except $\mathrm{CN}$, were kept constant at the start of injection, the piston compression would increase the pressure and temperature that influences ignition, resulting in uncertainties when correlating the ignition delay to $\mathrm{CN}$. In addition, different latent heats for vaporization of various fuels may lead to different degrees of charge cooling, affecting somewhat the ignition delay. Since an accurate prediction of ignition delays using a simple equation is essential for model-based control of engine combustion, especially in the development of multi-fuel-compatible engines, further investigations into the correlation between the ignition delay and fuel ignitability considering the effects of pressure and temperature at ignition are necessary.

Figure 4 shows the combustion phasing as a function of ignition delays. The combustion phasing is linearly correlated to the ignition delay with $\mathrm{R}^{2}$ up to 0.964 . Since the combustion phasing includes information about burning duration when the ignition delay is known, it is used as a variable for evaluations of the in-cylinder peak pressure $\left(P_{\max }\right)$, exhaust gas emissions, and thermal efficiency in Section 3.2.

Note that no significant influences of fuel volatility and viscosity on either the ignition delay (Fig. 3) or the combustion phasing (Fig. 4) could be identified.

\subsection{Peak pressure, exhaust gas emissions and thermal efficiency as a function of combustion phasing}

Figure 5 shows the in-cylinder peak pressure, $P_{\max }$, and the crank angle of $P_{\max }, \theta_{p \max }$, as a function of combustion phasing. Excluding GTL, both $P_{\max }$ and $\theta_{\text {pmax }}$ can be linearly correlated to the combustion phasing with high $\mathrm{R}^{2}$. 
For GTL, despite the relatively early combustion phasing, $\theta_{\text {pmax }}$ is retarded from and $P_{\max }$ shifts to below the regression lines. This can be attributed to the significant amount of after-burning for GTL as shown by the rate of heat release (ROHR) in Fig. 6. With the high kinematic viscosity and low volatility of GTL, the early fuel injection could lead to liquid film formation on the chamber surface; further, with the very high ignitability leading to relatively early ignition, these liquid fuels with insufficient premixing time would be a source of the diffusive combustion-like after-burning.

Shown in Figure 7 is the exhaust gas emissions as a function of combustion phasing. Noteworthy is that there are no smoke emissions (results not shown) from any of the test fuels in the experiments. Despite the significant amount of after-burning, the high contents of n-paraffins in GTL would result in reduced soot emissions. Moreover, as indicated by the relatively high NOx, high temperatures could play a role in the burn-out of soot particles before exhaustion from the engine for GTL. The NOx decreases exponentially with retarded combustion phasing, owing to the lowered peak temperature as well as the shortened residence time in high temperatures (Fig. 6).

Emissions of UHC and CO also show a dominant dependence upon combustion phasing, and CO is linearly dependent upon combustion phasing with $\mathrm{R}^{2}$ up to 0.908 . However, there are great fluctuations in UHC, which may largely be due to the differences in the fuel volatilities. Fuel-air over-mixing at zones near the injector tip has been observed in experiments with both constant-volume vessels [34] and optical engines [35] under conditions simulating diesel LTC, and these mixtures are too lean to support combustion, becoming a source of UHC emissions [36]. With higher volatility, fuel droplets would vaporize and lose the forward moments more quickly, remain upstream in the spray jet, and over-mix with ambient air. On the other hand, fuels of lower volatility are more likely to form a liquid film along the combustion chamber wall, which may become a source of the UHC emissions. Moreover, LTHR reactions, which have been reported as one of the possible sources of UHC [27, 37], might be significantly affected by fuel additives, but further investigations are necessary to address this issue.

Figure 8 shows the indicated thermal efficiency as a function of combustion phasing. The fluctuations in the indicated thermal efficiency can be largely attributed to uncertainties in the measurements of the fuel flow rate, while it may also to some degree be due to the variations in combustion efficiency that can be estimated from the UHC and CO emissions. Despite the fluctuations, however, the indicated thermal efficiency is well within the trends as a function of the combustion phasing. A polynomial fitting to the data shows that the indicated thermal efficiency peaks at the combustion phasing around TDC. This can be attributed to a balanced result of the combustion efficiency, the degree of constant volume heat release, and the cooling loss. 


\subsection{Smooth operating load range of premixed low-temperature combustion}

The upper load limit of premixed LTC is usually defined by the maximum allowable rate of pressure rise $\left((d p / d \theta)_{\max }\right)$ that depends on the engine type and operating conditions [7]. In this study, the upper load limit is defined as $(d p / d \theta)_{\max }$ of $1.0 \mathrm{MPa} /{ }^{\circ} \mathrm{CA}$ based on the perceived noise level, and the lower load limit is defined as $5 \%$ of the coefficient of variation in IMEP $\left(\mathrm{COV}_{\text {IMEP }}\right)$. Note that the LTC here is defined as low-temperature combustion without smoke emissions.

Figure 9 shows a comparison of the smooth operating load range as a function of $\mathrm{CN}, \mathrm{PCN}$, and the ignition delay. At $\mathrm{CN}$ or PCN > 40, the effects of $\mathrm{CN}$, PCN on both the upper and lower load limits are small, despite some fluctuations. At $\mathrm{CN}$ or PCN <40, both of the load limits significantly increase, but there are large fluctuations with small variations in $\mathrm{CN}$, while the load limits exhibit a stronger correlation with PCN and the actual ignition delay. This agrees well with the previous discussion regarding the effects of fuel ignitability measures on the ignition delay. Noteworthy is that since the low load limit increases more steeply than the high load limit, the smooth operating load range in the smokeless LTC mode becomes narrow at PCN $<40$. Here since both the injection timing and intake oxygen concentration are held constant, there should be some potentials for expansion of the operational load range with varying these two parameters.

Figure 10 shows the operation load range: (a) low load limit (b) high load limit with combustion phasing at TDC for two intake oxygen concentrations: $10 \%$ and $16 \%$. For comparison, the data under the conditions with fixed injection timing at $30{ }^{\circ} \mathrm{CA}$ BTDC and intake oxygen concentration at $14 \%$ are also plotted. Optimization of injection timing for CA50 at TDC can extend the low load limit to lower loads at PCN $<40$. Increasing the intake oxygen concentration to $16 \%$ can further expand the low load limit at $\mathrm{PCN}<40$, but the higher intake oxygen concentration results in several times higher NOx emissions for all fuels. It should be mentioned that $0.2 \mathrm{MPa}$ IMEP is near idling operation at $1320 \mathrm{rpm}$ and the low load limit cannot be further extended with higher intake oxygen concentration at $\mathrm{PCN}>40$.

To control CA50 at TDC at $14 \%$ intake oxygen concentration, the injection timing must be later than $30{ }^{\circ} \mathrm{CA}$ BTDC at the high load limit, resulting in the shorter ignition delay. As a result, at $\mathrm{PCN}<40$, the increases in combustible mixtures lead to decreases in the high load limit. At higher PCNs, despite the retarded CA50 compared to the case of fuel injection at $30{ }^{\circ} \mathrm{CA} \mathrm{BTDC}$, the high load limit cannot be significantly extended. Particularly, at PCN $>50$, though the maximum rate of pressure rise is lower than $1.0 \mathrm{MPa} /{ }^{\circ} \mathrm{CA}$, the shortened ignition delay results in insufficient fuel-air mixing, causing smoke emissions to be a limitation of the load expansion. With decreasing the intake oxygen concentration to $10 \%$, the high load limit can be significantly extended, for a wide range of fuel ig- 
nitability, but this would be at the expenses of significant increases in the UHC and CO emissions [19-26]. One may note again that at $\mathrm{PCN}>50$, the maximum rates of pressure rise are lower than $1.0 \mathrm{MPa} /{ }^{\circ} \mathrm{CA}$ at $10 \%$ intake oxygen, suggesting potentials for further expansion of the high load limit. However, higher loads need more fuel injected into the cylinder, and this would result in shorter ignition delay and higher in-cylinder temperature. As a result, smoke emissions become a limitation of the load expansion. At $25 \mathrm{PCN}$, the maximum rate of pressure rise is also apparently lower than $1.0 \mathrm{MPa} /{ }^{\circ} \mathrm{CA}$. This can be attributed to the fact that though the fuel injection started at $30{ }^{\circ} \mathrm{CA}$ BTDC (further advanced injection timing will cause problems of the cylinder wall wetting by spray), CA50 occurred after TDC, causing the lowered maximum rate of pressure rise. Despite the very long premixed time and low maximum rate of pressure rise, the smokeless LTC cannot be achieved at higher loads, owing to the low oxygen concentration as well as the high content of aromatics in the fuel (KE2).

Despite the sacrificed combustion efficiency, lowered intake oxygen concentration can offer significant benefits in NOx reductions, in addition to expansion of the higher load limit. As shown in Fig. 10 (b), at the 10\% intake oxygen concentration, despite the higher load operations, the NOx emissions are suppressed to levels below $10 \mathrm{ppm}$ for all the test fuels. At 14\% intake oxygen concentration, with the low ignitability fuels, the NOx emissions are at levels above $100 \mathrm{ppm}$ for both the cases of fixed injection timing and constant CA50 at TDC. However, with the high ignitability fuels, there are significantly lower levels of NOx emissions for the constant CA50 case than the fixed injection timing case. This difference in NOx emissions can be attributed to the fact that while the higher fuel ignitability leads to earlier ignition and then longer residence time in high temperatures for fixed injection timing, the ignition timing may not significantly change with increased fuel ignitability for constant CA50.

\subsection{Effect of fuel volatility}

From Figs. 3 to 9, it can be inferred that the effect of fuel volatility is small while the ignitability is the dominant factor influencing the ignition delay, combustion phasing, exhaust gas emissions, and the operational load range of the smokeless LTC mode. Further, as shown in Figs. $11 \& 12$, for GS2, KE, and DF3, which have a 50\% distillation temperature $\left(\mathrm{T}_{50}\right)$ ranging from 140 to $265^{\circ} \mathrm{C}$, the ignition delays are almost identical, and there are almost no differences in the high load limits and indicator diagrams. These results agree well with the reported findings from the experiments with either real diesel engines [25, 38-40] or constant volume combustion vessels in premixed LTC modes [41].

\subsection{Operational injection timing range for various fuel ignitabilities}


Modern electronically-controlled common-rail fuel injection technologies have enabled a dynamic control of fuel injection timing for optimized engine performance and exhaust gas emissions. While closed-loop control based on in-cylinder pressure feedback offers a very powerful tool in implementing a premixed LTC mode in diesel engines compliant with various fuel properties [27], however, the high cost of state-of-the-art pressure sensors is still a major hurdle for a widespread use of the closed-loop control technologies. Comparatively, a common injection timing range for a variety of fuel ignitabilities, where similar engine performances and exhaust gas emissions can be obtained, would be very desirable in engine design, considering fuel diversification.

In this study, the operational injection timing range in the diesel LTC mode for various fuel ignitabilities was examined. The results are plotted in Figure 13 as contour maps of the maximum rate of pressure rise, smoke, and NOx emissions with PCN as the abscissa and injection timing as the ordinate. Since there are no clear trends of UHC and $\mathrm{CO}$ emissions, these emissions are not shown in the figure. In the experiments, the engine load and intake oxygen concentration were held constant at 0.4 MPa IMEP and 14\%, respectively. The injection timing was swept from the stable operating limit $\left(\mathrm{COV}_{\mathrm{IMEP}}=5 \%\right)$ to the advanced limit $\left(30{ }^{\circ} \mathrm{CA} \mathrm{BTDC}\right)$. In each figure, the upper and lower dashed lines denote the stable combustion and abrupt combustion limits $\left((d p / d \theta)_{\max }=1.0 \mathrm{MPa}\right)$, respectively, and the contours were obtained from the correlative function fitting to the experimental data. At PCN > 40, almost all of the smokeless combustion zone fall in the abrupt combustion area, and the NOx emissions here are higher than $100 \mathrm{ppm}$. At $40<\mathrm{PCN}<56$, which represents the $\mathrm{CN}$ range of commercial diesel fuels, stable LTC operation can be realized for a relatively wide range of injection timings from $5 \sim 18{ }^{\circ} \mathrm{CA}$ BTDC, despite some smoke emissions with levels below $8 \%$. This suggests the adequate robustness of the premixed LTC mode to fuel diversification in the above ignitability range. It must be noted that in the above stable operating range the change of indicated thermal efficiency with the injection timing sweep is maintained within $3 \%$. At $\mathrm{PCN}<40$, smokeless, low-NOx, and stable operation can be realized for a wide injection timing range. The maximum rate of pressure rise and the NOx emissions decrease with PCN decreasing. At PCN $<35$, however, the injection timing for the stable operating limit shifts drastically to the earlier side. With the injection timing earlier than $25{ }^{\circ} \mathrm{CA}$ BTDC both the maximum rate of pressure rise and NOx decrease somewhat. This may be attributed to the fact that the fuel-air mixtures become too lean to support a more complete combustion, owing to the very long premixing time with the low fuel ignitability and the early fuel injection timings. However, despite the decrease in the rate of pressure rise and NOx emissions, as a result of decreased combustion efficiency, deterioration of the thermal efficiency is larger than $3 \%$.

Figure 14 shows the timings of the earliest and latest ignition timings with the injection timing sweeping for 
the various fuels under the same conditions as Fig. 13. Expressed differently, the range between the two limits as shown in Fig. 14 indicates the controllable ignition timings with the injection timing sweep. The controllable ignition timing range becomes significantly narrower with decreased fuel ignitability, particularly at PCN $<45$. This indicates that at the lower fuel ignitability resulting in the longer ignition delays, the sensitivity of the ignition timing to the advance or retardation in fuel injection timing becomes lower.

\section{CONCLUSIONS}

The effects of fuel properties including ignitability and volatility on the characteristics of diesel engines operated in the moderately-advanced-injection LTC mode have been studied. The major conclusions may be summarized as follows:

- While the ignition delay increases with $\mathrm{CN}$ decreasing in a piecewise linear manner, at $\mathrm{CN}<40$ the correlation between the ignition delay and CN becomes weak at the LTC mode. The predicted cetane number (PCN) determined from fuel molecular structure analysis can be fitted to the ignition delay with $\mathrm{R}^{2}$ up to 0.9326 , suggesting a better potential as a fuel ignitability measure than the traditional $\mathrm{CN}$ determinations over a wide range including low ignitability.

- Despite the better potential of PCN as a fuel ignitability measure, the analysis of fuel molecular structure using the ${ }^{1} \mathrm{H}$ - NMR spectroscopy in the present study cannot discriminate the difference between straight and cyclic alkanes, and it fails to evaluate the effect of oxygen in oxygenate fuels on the fuel ignitability, resulting in PCN to be an inaccurate measure for fuels containing significant amount of naphthenes or oxygenate components. This issue should be addressed in the future work.

- Combustion phasing (CA50), which is linearly dependent on the ignition delay with $\mathrm{R}^{2}$ up to 0.964 , is demonstrated to be a very good indicator to estimate the exhaust gas emissions, thermal efficiency, and operating load range in the low-temperature combustion (LTC) mode.

- The operation load range of smokeless LTC depends more on the actual ignition delay and PCN rather than $\mathrm{CN}$, particularly for low ignitability fuels.

- Above PCN 40, the effects of fuel ignitability on both the upper and lower load limits are small. Below PCN 40 , it is possible to extend the non-sooting, low-noise, and stable LTC operation significantly to higher loads. However, the low load limit increases more steeply below PCN 40, resulting in a narrowed load range in the 
smokeless LTC mode under the conditions with fixed injection timing at $30{ }^{\circ} \mathrm{CA}$ BTDC and intake oxygen concentration at $14 \%$.

- Holding CA50 at TDC by varying the fuel injection timing for different ignitabilities, lower load limits are possible below PCN 40, resulting in expanded operational range. An increase in the intake oxygen concentration is effective to further expand the low load limit, but this would be at the expense of increases in NOx emissions.

- Decreasing the intake oxygen concentration to $10 \%$, the high load limit can be significantly extended for a wide range of fuel ignitabilities. However, further increases in injection quantity will cause smoke emissions, and further decreases in the intake oxygen concentration would cause dramatic increases in THC and CO, limiting the high load limit for practical use.

- In the LTC mode, the effects of fuel volatility are much smaller than the effects of fuel ignitability. The dominant role of fuel ignitability is to affect the ignition delay and combustion phasing. With pre-optimized values of injection timing and combustion phasing matched through a closed-loop control based on in-cylinder pressure feedback, the effects of fuel ignitability on the characteristics of LTC are not significant.

- At PCN $40 \sim 56$ and for injection timings from $5 \sim 18{ }^{\circ} \mathrm{CA}$ BTDC, efficient, low-NOx, and stable LTC can be achieved, despite some smoke emissions. Advancing the injection timing is effective for smokeless combustion, but this is at the expense of higher pressure rise rates and NOx levels. At PCN $<40$, smokeless and low NOx combustion can be realized for a wide injection timing range, but the combustion efficiency deteriorates significantly with too early fuel injection.

- The possible ignition timing range by the injection timing control becomes narrower with the fuel ignitability decreasing, owing to reductions in the sensitivity of the ignition timing to the fuel injection timing for lower fuel ignitabilities.

\section{REFERENCES}

1 Kalghatgi, G.T., Risberg, P., and Ångström, H-E. Advantages of fuels with high resistance to auto-ignition in late-injection, low-temperature, compression ignition combustion. SAE paper 2006-01-3385, 2006.

2 Kalghatgi, G.T., Risberg, P., and Ångström, H-E. Partially pre-mixed auto-ignition of gasoline to attain low smoke and low NOx at high load in a compression ignition engine and comparison with a diesel fuel. SAE pa- 
per 2007-01-0006, 2007.

3 Weall, A.J., and Collings, N. Investigation into partially premixed combustion in a light duty multi cylinder diesel engine fuelled with a mixture of gasoline and diesel. SAE paper 2007-01-4058, 2007.

4 Sung, K., Kim, J., and Reitz, R.D. Experimental study of pollutant emission reduction for near-stoichiometric diesel combustion in a three-way catalyst. Inter. J. Engine Res., 2009, 10(5), 394-357.

5 Dec, J.E. A conceptual model of DI diesel combustion based on laser-sheet imaging. SAE paper 970873, 1997.

6 Emissions regulations may be found at: http://www.dieselnet.com/standards/.

7 Dec, J.E. Advanced compression-ignition engines - understanding the in-cylinder processes. Proc. Combst. Inst., 2009, 32, 2727-2742.

8 Yao, M., Zheng, Z., and Liu, H. Progress and recent trend in homogeneous charge compression ignition (HCCI) engines. Prog. Energ. Combst. Sci., 2009, 35, 398-437.

9 Takeda, Y., and Nakagome, K. Emission characteristics of premixed lean diesel combustion with extremely early staged fuel injection. SAE paper 961163, 1996.

10 Akagawa, H., Miyamoto, T., Harada, A., Sasaki, S., Shimazaki, N., and Hashizume, T. Approaches to solve problems of the premixed lean diesel combustion. SAE paper 1999-01-0183, 1999.

11 Hasegawa, R., and Yanagihara, H. HCCI combustion in DI diesel engine. SAE paper 2003-01-0745, 2003.

12 Kimura, S., Aoki, O., Ogawa, H., Muranaka, S., and Enomoto, Y. New combustion concept for ultra-clean and high-efficiency small DI diesel engines. SAE paper 1999-01-3681, 1999.

13 Akihama, K., Takatori, Y., Inagaki, K., Sasaki, S., and Dean, A.M. Mechanism of the smokeless rich diesel combustion by reducing temperature. SAE paper 2001-01-0655, 2001.

14 Shimazaki, N., Tsurushima, T., and Nishimura, T. Dual-mode combustion concept with premixed diesel combustion by direct injection near top dead center. SAE paper 2003-01-0742, 2003.

15 Neely, G.D., Sasaki, S., Huang, Y., Leet, J.A., and Stewart, D.W. New diesel emission control strategy to meet US Tier 2 emissions regulations. SAE paper 2005-01-1091, 2005.

16 Alriksson, M., Rente, T., and Denbratt, I. Low soot, low NOx in a heavy duty diesel engine using high levels of EGR. SAE Paper 2005-01-3836, 2005.

17 Kook, S., Bae, C., Miles, P., Chio, D., and Picket, L.M. The influence of charge dilution and injection timing on low-temperature diesel combustion and emissions. SAE paper 2005-01-3837, 2005.

18 Noehre, C., Anderson, M., Johansson, B., and Hultqvist, A. Characterization of partially premixed combus- 
tion. SAE paper 2006-01-3412, 2006.

19 Li, T., Izumi, H., Shudo, T., Ogawa, H., and Okabe, Y. Characterization of low temperature diesel combustion with various dilution gases. SAE Trans. J. Engines, 2007, 116 (3), 120-131.

20 Ogawa, H., Li, T., and Miyamoto, N. Characteristics of low temperature and low oxygen diesel combustion with ultra-high EGR. Inter. J. Engine Res., 2007, 8(4), 365-378.

21 Li, T., and Ogawa, H. Regulated emissions and speciated hydrocarbon emissions from smokeless low temperature combustion diesel engines with ultra-high EGR and exhaust oxidation catalyst. Proc. IMechE. J. Automobile Engineering, 2009, 223 (D5), 673-683.

22 Li, T., Suzuki, M., and Ogawa, H. The effect of two-stage injection on unburned hydrocarbon and carbon monoxide emissions in smokeless low temperature diesel combustion with ultra-high exhaust gas recirculation. Inter. J. Engine Res., 2010, 11(5), 1468-0874.

23 Li, T., Suzuki, M., and Ogawa, H. Effects of in-cylinder temperature and fuel air mixing quality on smokeless low temperature diesel combustion. Proc. COMODIA, 2008, 7, 135-142.

24 Li, T., Suzuki, M., and Ogawa, H. Characteristics of smokeless low temperature diesel combustion in various fuel-air mixing and expansion of operating load range. SAE paper 2009-01-1449, 2009.

25 Li, T., Okabe, Y., Izumi, H., Shudo, T., and Ogawa, H. Dependence of ultra-high EGR and low temperature diesel combustion on fuel properties. SAE paper 2006-01-3387, 2006.

26 Li, T., Suzuki, M., and Ogawa, H. Effects of ethyl tert-butyl ether addition to diesel fuel on characteristics of combustion and exhaust emissions of diesel engines. Fuel, 2009, 88, 2017-2024.

27 Ickes, A.M., Bohac, S.V., and Assanis, D.N. Effect of fuel cetane number on a premixed diesel combustion mode. Int. J. Engine Res., 2009, 10(4), 251-263.

28 Suzuki, T., Murase, M., and Akasaka, Y. A study on the applicability of parameters based on molecular structure to combustion characteristics. SAE paper 2010-01-0736, 2010.

29 Heywood, J. B. Internal combustion engines fundamentals, McGram-Hill, Inc., 1988, p.510.

30 Shipinski, J., Meyers, P.S., and Uyehara, O.A. A spray droplet model for Diesel combustion. Inst. Mech. Eng., 1960, 184 (Part 3J), 28-35.

31 Henein, N.A., and Bolt, J.A. Correlation of air charge temperature and ignition delay for several fuels in a diesel engine. SAE paper 690252, 1969.

32 Aligrot., C, Champoussin, J.C., Guerrassi, N., and Claus, G. Prediction of self-ignition delay of different liquid diesel fuels. Proc. COMODIA, 1994, 3, 331-336. 
33 Pilling, M.J. Low-Temperature Combustion and Autoignition, Elsevier, 1997.

34 Musculus, M., Lachaux, T., Pickett, L., and Idicheria, C. End-of-injection over-mixing and unburned hydrocarbon emissions in low-temperature-combustion diesel engines. SAE paper 2007-01-0907, 2007.

35 Kim, D., Ekoto, T., Colban, W., and Miles, P. In-cylinder CO and UHC imaging in a light-duty diesel engine during PPCI low-temperature combustion. SAE paper 2008-01-1602, 2008.

36 Greeves, G., Khan, T., Wang, C., and Fenne, I. Origins of hydrocarbon emissions from diesel engines. SAE paper 770259, 1997.

37 Szybist, J., and Bunting, B. Cetane number and engine speed effects on diesel HCCI performance and emissions. SAE paper 2005-01-3723, 2005.

38 Risberg, P., Kalghatgi, G.T., and Ångström, H-E. Auto-ignition quality of diesel-like fuels in HCCI engines. SAE paper 2005-01-2127, 2005.

39 Bessonette, P.W., Schleyer, C.H., Duffy, K.P., Hardy, W.L., and Liechty, M.P. Effects of fuel property changes on heavy-duty HCCI combustion. SAE paper 2007-01-0191, 2007.

40 Kalghatgi, G.T., Hildingsson, L., Johansson, B., and Harrison, A. Some effects of fuel autoignition quality and volatility in premixed compression ignition engines. SAE paper 2010-01-0607, 2010.

41 Kook, S., and Pickett, L.M. Effect of fuel volatility and ignition quality on combustion and soot formation at fixed premixing conditions. SAE Paper 2009-01-2643, 2009.

\section{APPENDIX}

\section{Notation}

$P_{i n j} \quad$ : injection pressure

$P_{\max } \quad$ : cylinder peak pressure

$(d p / d \theta)_{\max }:$ maximum rate of pressure rise

$t_{i n j} \quad$ : injection timing

$\theta_{\text {Pmax }} \quad$ : location of $P_{\max }$

$\theta_{\text {pre }} \quad$ : premixing time

\section{Subscript}

in : intake

$\max \quad$ : maximum 
pre : premixing

inj $\quad$ : fuel injection

\section{Acronyms}

${ }^{1} \mathrm{NMR}$ : proton nuclear magnetic resonance spectroscopy

ATDC : after top dead center

BTDC : before top dead center

CA50 : combustion phasing defined by the crank angle of $50 \%$ accumulative heat release

CFR : cooperative fuel research engine

CN : cetane number

CO : carbon monoxide

COV : coefficient of variation

DF : diesel fuel

DI : direct injection

EGR : exhaust gas recirculation

GS : gasoline

GTL : gas-to-liquid

ICE : internal combustion engines

IMEP : indicated mean effective pressure

KE : kerosene

LTC : low temperature combustion

LTHR : low temperature heat release

NOx : oxides of nitrogen

PCN : predicted cetane number

ROHR : rate of heat release

$\mathrm{T}_{50}: 50 \%$ distillation temperature

TDC : top dead center

UHC : unburned hydrocarbons

$\mathrm{O}_{2 \mathrm{in}} \quad$ : intake oxygen concentration

${ }^{\circ} \mathrm{CA}$ : crank angle degree 
List of captions for the tables

Table 1 Engine specifications

Table 2 Experimental conditions

Table 3 Properties of test fuels 
Table 1 Engine specifications

Cylinder number

Bore $\times$ stroke

Displacement

Piston cavity shape

Rated power

Compression ratio

Swirl ratio

Intake system

Valve number

Fuel injection system

Nozzle hole
1

$\varnothing 110 \times 106 \mathrm{~mm}$

$1007 \mathrm{~cm}^{3}$

Toroidal

11.8 kW @ 2200 rpm

16.0

2.2

Naturally aspirated

2

Common rail system

$\varnothing 0.20 \times 4-150^{\circ}$

Table 2 Experimental conditions

\begin{tabular}{ll}
\hline Engine speed & $1320 \mathrm{rpm}$ \\
Coolant temperature & $80{ }^{\circ} \mathrm{C}$ \\
Injection pressure & $60 \mathrm{MPa}$ \\
Injection quantity & Dynamically controlled for \\
& various engine loads \\
& $\bullet$ Constant at $30^{\circ} \mathrm{CA}$ BTDC \\
Injection timing & Dynamically controlled for \\
& constant CA50 at TDC \\
& - Sweep in $3{ }^{\circ} \mathrm{CA}$ increments \\
& from stable operating limit \\
& to $30^{\circ} \mathrm{BTDC}$ \\
& $30 \pm 3{ }^{\circ} \mathrm{C}$ \\
Intake temperature & $10 \%, 14 \%, 16 \%$ \\
Intake oxygen concentration &
\end{tabular}


Table 3 Properties of test fuels

\begin{tabular}{|c|c|c|c|c|c|c|c|}
\hline Fuels & $\begin{array}{l}\text { Density } \\
@ 15^{\circ} \mathrm{C} \\
{\left[\mathrm{g} / \mathrm{cm}^{3}\right]}\end{array}$ & $\begin{array}{c}\text { Kinematic } \\
\text { viscosity } \\
@ 30^{\circ} \mathrm{C} \\
{\left[\mathrm{mm}^{2} / \mathrm{s}\right]} \\
\end{array}$ & $\begin{array}{l}\mathrm{T}_{50}{ }^{\mathrm{a}} \\
{\left[{ }^{\circ} \mathrm{C}\right]} \\
\end{array}$ & $\begin{array}{c}\mathrm{LHV}^{\mathrm{b}} \\
{[\mathrm{MJ} / \mathrm{kg}]}\end{array}$ & $\mathrm{CN}$ & $\mathrm{PCN}$ & Fuel description \\
\hline GS0 & 0.733 & - & 92 & 45.6 & 11 & - & Regular gasoline \\
\hline GS1 & 0.742 & - & 106 & 45.8 & 35 & 30 & GS $+20 \%$ n-paraffins \\
\hline GS2 & 0.749 & - & 140 & 46.2 & 45 & 45 & GS $+40 \%$ n-paraffins \\
\hline GS3 & 0.684 & - & $98^{\mathrm{c}}$ & 48.0 & 60 & 61 & $\mathrm{PRFO}^{\mathrm{d}}$ \\
\hline GS4 & 0.687 & - & $99^{\mathrm{c}}$ & 47.9 & 39 & 40 & PRF40 ${ }^{\mathrm{d}}$ \\
\hline DF0 & 0.830 & 3.48 & 277 & 45.7 & 53 & 58 & Diesel fuel \\
\hline DF1 & 0.840 & 1.80 & 259 & 44.8 & 36 & 35 & $\mathrm{DF}+40 \%$ gasoline \\
\hline DF2 & 0.837 & 2.48 & 258 & 45.2 & 49 & 47 & $\mathrm{DF}+20 \%$ aromatics \\
\hline DF3 & 0.820 & 2.66 & 263 & 45.9 & 45 & 58 & $\mathrm{DF}+20 \%$ naphthenes \\
\hline DF4 & 0.805 & 2.35 & 268 & 44.6 & 49 & 68 & $\mathrm{DF}+20 \% \mathrm{ETBE}^{\mathrm{e}}+20 \% \mathrm{GTL}$ \\
\hline DF5 & 0.814 & 2.29 & 262 & 44.4 & 47 & 65 & $\mathrm{DF}+20 \% \mathrm{ETBE}^{\mathrm{e}}$ \\
\hline DF6 & 0.821 & 3.65 & 281 & 46.0 & 59 & 61 & $\mathrm{DF}+20 \% \mathrm{GTL}$ \\
\hline DF7 & 0.841 & 3.80 & 294 & 42.9 & 54 & 55 & $\mathrm{DF}+20 \% \mathrm{FAME}^{\mathrm{f}}$ \\
\hline DF8 & 0.822 & 3.04 & 258 & 43.1 & 55 & 58 & $\mathrm{DF}+20 \%$ naphthenes \\
\hline DF9 & 0.819 & 3.12 & 265 & 43.1 & 61 & 55 & $\mathrm{DF}+20 \%$ olefins \\
\hline DF10 & 0.778 & - & $261^{\mathrm{c}}$ & 47.1 & 45 & 45 & $\mathrm{CN} 45^{\mathrm{g}}$ \\
\hline DF11 & 0.776 & - & $273^{\mathrm{c}}$ & 47.1 & 70 & 72 & $\mathrm{CN} 70^{\mathrm{g}}$ \\
\hline DF12 & 0.776 & - & $265^{\mathrm{c}}$ & 47.1 & 53 & - & $\mathrm{CN}_{5} 3^{\mathrm{g}}$ \\
\hline KE0 & 0.796 & 1.39 & 196 & 46.0 & 45 & 49 & Kerosene \\
\hline KE1 & 0.809 & 1.08 & 189 & 45.1 & 37 & 34 & $\mathrm{KE}+20 \%$ aromatics \\
\hline KE2 & 0.823 & - & 169 & 46.2 & 38 & 25 & $\mathrm{KE}+40 \%$ aromatics \\
\hline KE3 & 0.787 & 1.43 & 202 & 46.3 & 51 & 56 & $\mathrm{KE}+20 \%$ n-paraffins \\
\hline GTL & 0.830 & 4.39 & 300 & 46.9 & 75 & 73 & Gas-To-Liquid \\
\hline $\begin{array}{l}\text { a } 50 \% \text { di } \\
\text { c Estima } \\
\text { e ETBE: } \\
\text { g Refere }\end{array}$ & $\begin{array}{l}\text { yl } \\
\text { yl tertiary } \\
\text { fuel (blen }\end{array}$ & $\begin{array}{l}\text { ure } \\
\text { oints of fuel co } \\
1 \text { ether } \\
\text { hexadecane a }\end{array}$ & ents & \multicolumn{4}{|c|}{$\begin{array}{l}\text { b Lower heating value } \\
\text { d Primary reference fuel (blends of n-heptane and i-octan } \\
\text { f FAME: Fatty acid methyl ester }\end{array}$} \\
\hline
\end{tabular}




\section{List of captions for the illustrations}

Fig. 1 Assignment of hydrogen types on ${ }^{1} \mathrm{H}-\mathrm{NMR}$ spectra.

Fig. 2 Correlation of predicted cetane number $(\mathrm{PCN})$ and measured cetane number $(\mathrm{CN})$.

Fig. 3 Ignition delay as a function of $\mathrm{CN}$ and PCN. The solid lines represent the best fitting and dashed lines for the piecewise linear approximation $\left(t_{i n j}=30^{\circ} \mathrm{CA} \mathrm{BTDC}, \mathrm{O}_{2 \text { in }}=14 \%, \mathrm{IMEP}=0.3 \mathrm{MPa}\right)$.

Fig. 4 Combustion phasing (CA50) as a function of ignition delay $\left(t_{i n j}=30{ }^{\circ} \mathrm{CA} \mathrm{BTDC}, \mathrm{O}_{2 i n}=14 \%\right.$, IMEP $=$ $0.3 \mathrm{MPa})$.

Fig. 5 In-cylinder peak pressure $\left(P_{\max }\right)$ and crank angle at $P_{\max }\left(\theta_{P_{\max }}\right)$ as a function of CA50 $\left(t_{i n j}=30{ }^{\circ} \mathrm{CA}\right.$ BTDC, $\mathrm{O}_{2 \text { in }}=14 \%$, IMEP $\left.=0.3 \mathrm{MPa}\right)$.

Fig. 6 Indicator diagrams for five fuels with various ignitabilities $\left(t_{i n j}=30{ }^{\circ} \mathrm{CA} \mathrm{BTDC}, \mathrm{O}_{2 \text { in }}=14 \%, \mathrm{IMEP}=0.3\right.$ $\mathrm{MPa})$.

Fig. 7 Exhaust gas emissions as a function of CA50 $\left(t_{i n j}=30^{\circ} \mathrm{CABTDC}, \mathrm{O}_{2 \text { in }}=14 \%\right.$, IMEP $\left.=0.3 \mathrm{MPa}\right)$.

Fig. 8 Indicated thermal efficiency as a function of CA50 ( $t_{i n j}=30^{\circ} \mathrm{CA}$ BTDC, $\mathrm{O}_{2 \text { in }}=14 \%$, IMEP $\left.=0.3 \mathrm{MPa}\right)$.

Fig. 9 Stable operating load range for smokeless, low-temperature combustion as a function of CN, PCN, and actual ignition delay $\left(t_{i n j}=30^{\circ} \mathrm{CA} \mathrm{BTDC}, \mathrm{O}_{2 \text { in }}=14 \%\right)$.

Fig. 10 Expansion of stable operating load range for smokeless, low-temperature combustion with holding combustion phasing constant at TDC and changing intake oxygen concentrations for various fuel ignitabilities (High load limit: $(d p / d \theta)_{\max }=1.0 \mathrm{MPa} /{ }^{\circ} \mathrm{CA}$, low load limit: $\mathrm{COV}_{\mathrm{IMEP}}=5 \%$ ).

Fig. 11 Ignition delay and high load limit as a function of $50 \%$ distillation temperature $\left(t_{i n j}=30{ }^{\circ} \mathrm{CA}\right.$ BTDC, $\mathrm{O}_{2 \text { in }}=14 \%$ ).

Fig. 12 Indicator diagrams for three fuels specified in Fig. 10.

Fig. 13 Injection timing range for stable, low-emission, and low-noise operation as a function of PCN (IMEP = $\left.0.4 \mathrm{MPa}, \mathrm{O}_{2 \text { in }}=14 \%\right)$.

Fig. 14 Ignition range for advantageous stable, low-emission, and low-noise operation as a function of PCN $\left(\mathrm{IMEP}=0.4 \mathrm{MPa}, \mathrm{O}_{2 \mathrm{in}}=14 \%\right)$. 


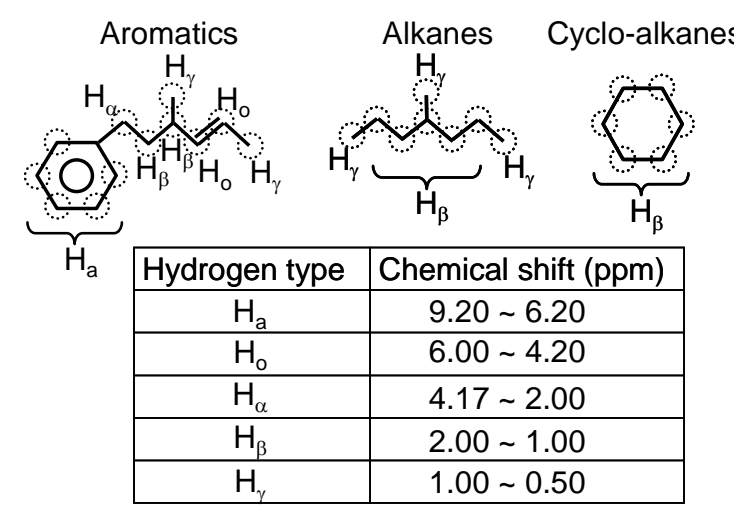

Fig. 1 Assignment of hydrogen types on ${ }^{1} \mathrm{H}-\mathrm{NMR}$ spectra. 


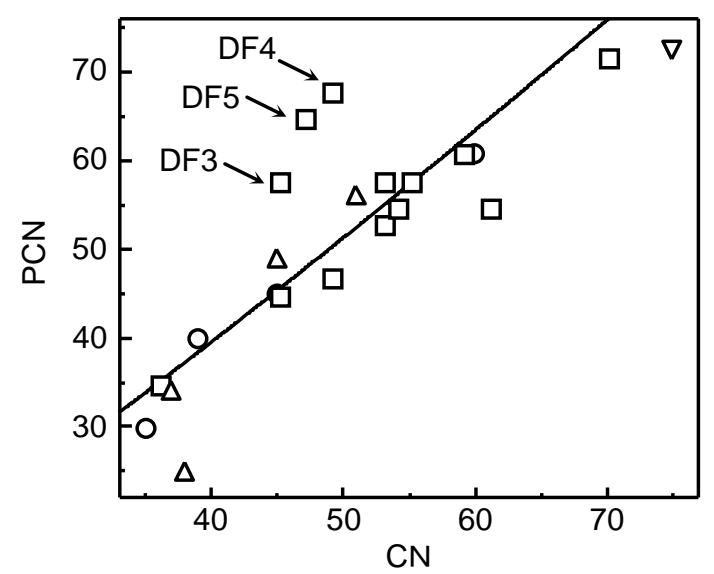

Fig. 2 Correlation of predicted cetane number $(\mathrm{PCN})$ and measured cetane number $(\mathrm{CN})$. 

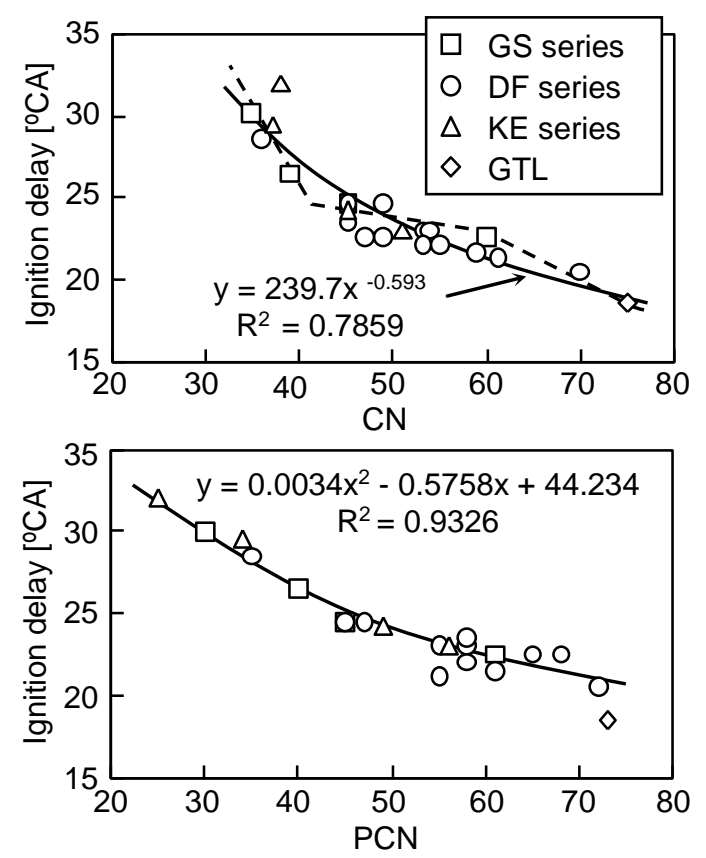

Fig. 3 Ignition delay as a function of CN and PCN. The solid lines represent the best fitting and dashed lines for the piecewise linear approximation $\left(t_{i n j}=30^{\circ} \mathrm{CA} \mathrm{BTDC}, \mathrm{O}_{2 \mathrm{in}}=14 \%\right.$, IMEP $\left.=0.3 \mathrm{MPa}\right)$. 


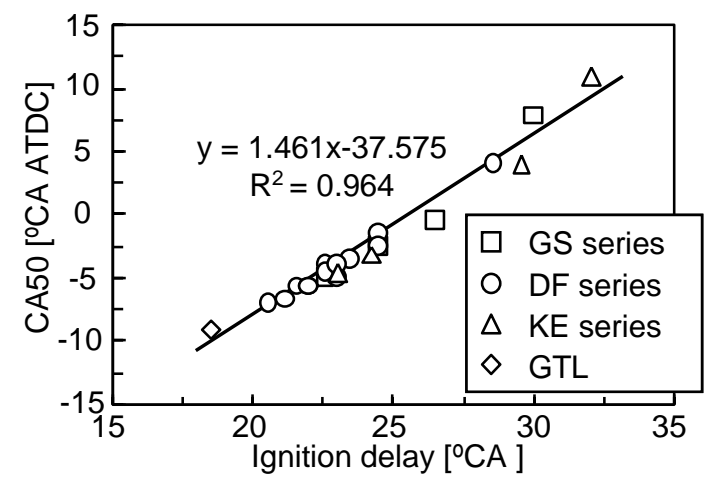

Fig. 4 Combustion phasing (CA50) as a function of ignition delay $\left(t_{i n j}=30{ }^{\circ} \mathrm{CA}\right.$ BTDC, $\mathrm{O}_{2 \mathrm{in}}=14 \%, \mathrm{IMEP}=0.3$ $\mathrm{MPa})$. 


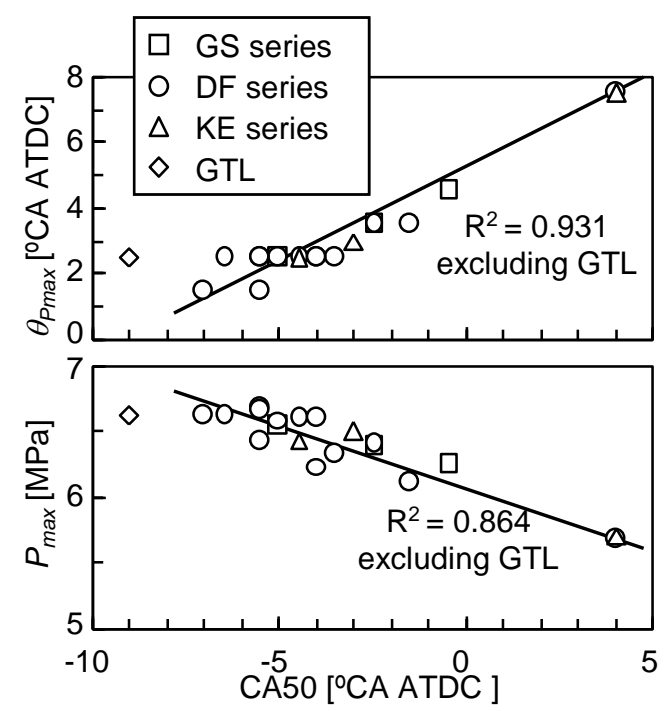

Fig. 5 In-cylinder peak pressure $\left(P_{\max }\right)$ and crank angle at $P_{\max }\left(\theta_{P_{\max }}\right)$ as a function of CA50 $\left(t_{i n j}=30{ }^{\circ} \mathrm{CA}\right.$ BTDC, $\mathrm{O}_{2 \text { in }}=14 \%$, IMEP $\left.=0.3 \mathrm{MPa}\right)$. 


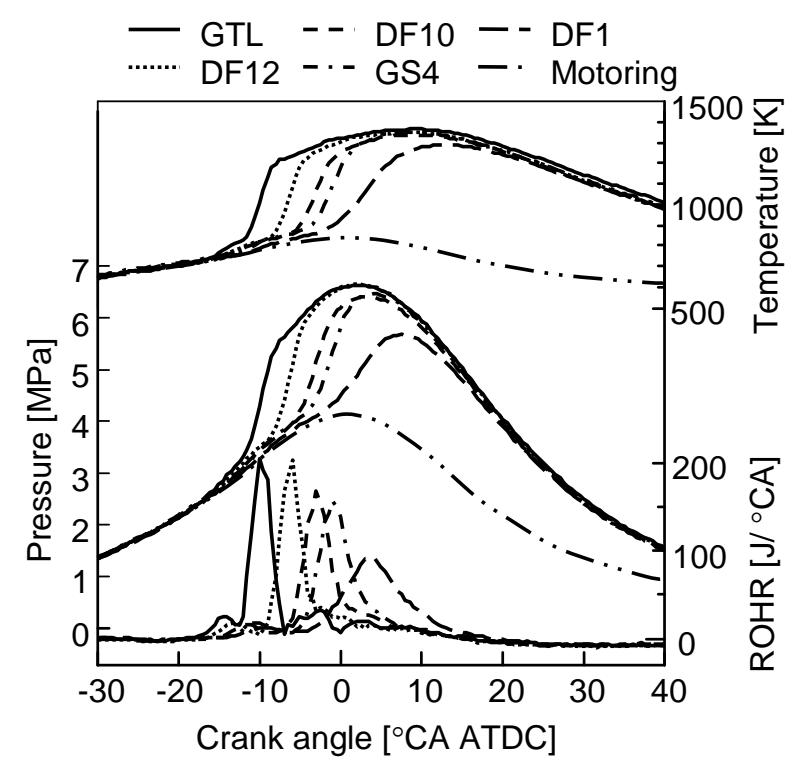

Fig. 6 Indicator diagrams for five fuels with various ignitabilities $\left(t_{i n j}=30{ }^{\circ} \mathrm{CA} \mathrm{BTDC}, \mathrm{O}_{2 \text { in }}=14 \%\right.$, IMEP $=0.3$ $\mathrm{MPa})$. 

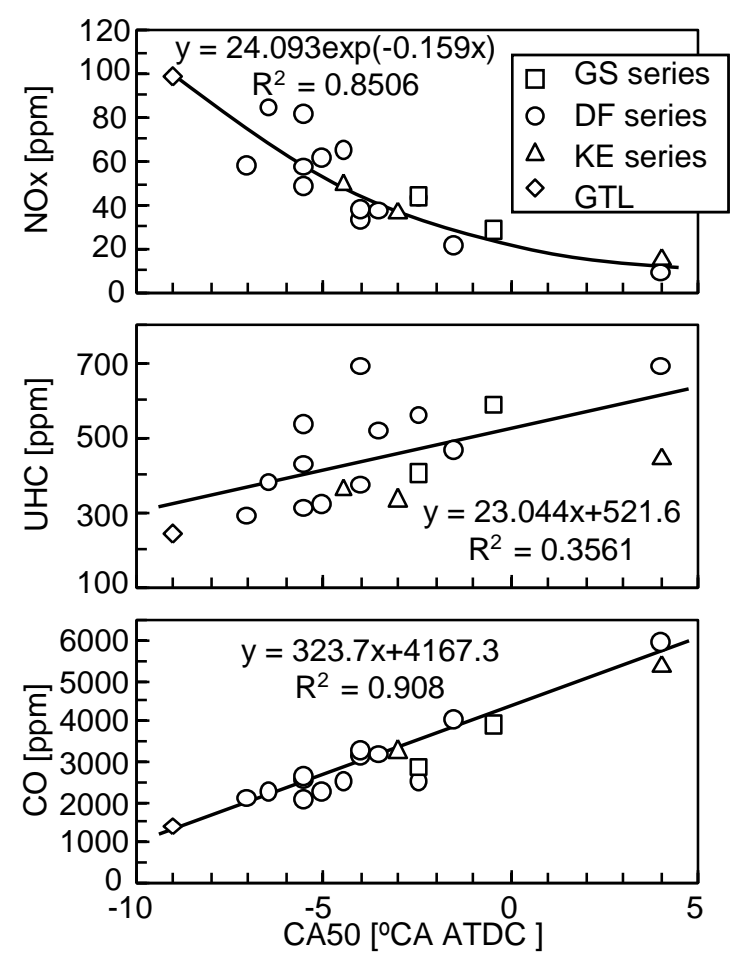

Fig. 7 Exhaust gas emissions as a function of CA50 $\left(t_{i n j}=30^{\circ} \mathrm{CA}\right.$ BTDC, $\mathrm{O}_{2 \text { in }}=14 \%$, IMEP $\left.=0.3 \mathrm{MPa}\right)$. 


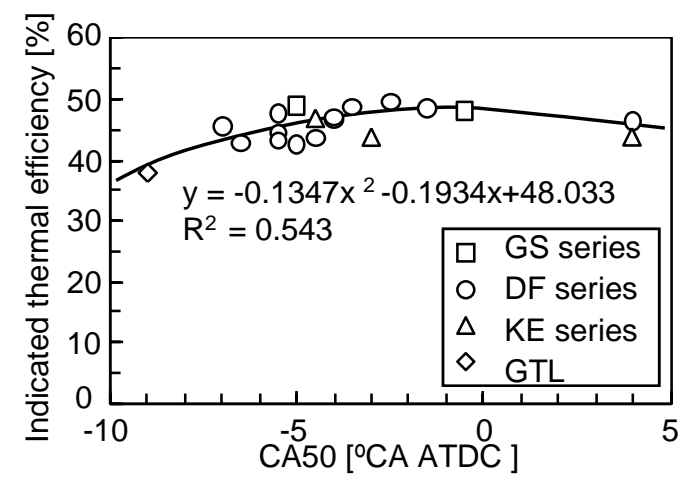

Fig. 8 Indicated thermal efficiency as a function of CA50 $\left(t_{i n j}=30{ }^{\circ} \mathrm{CA}\right.$ BTDC, $\mathrm{O}_{2 \text { in }}=14 \%$, IMEP $\left.=0.3 \mathrm{MPa}\right)$. 

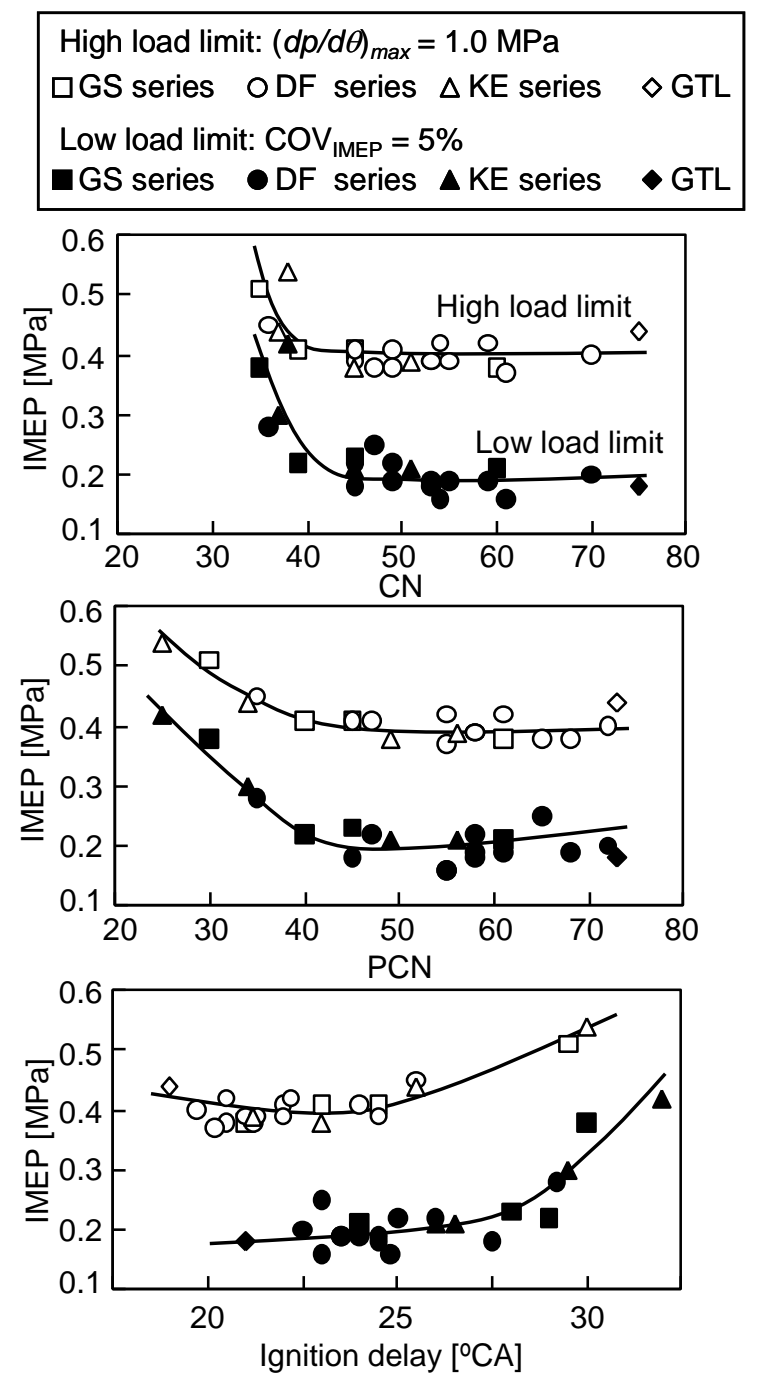

Fig. 9 Stable operating load range for smokeless, low-temperature combustion as a function of CN, PCN, and actual ignition delay $\left(t_{i n j}=30^{\circ} \mathrm{CA} \mathrm{BTDC}, \mathrm{O}_{2 \mathrm{in}}=14 \%\right)$. 

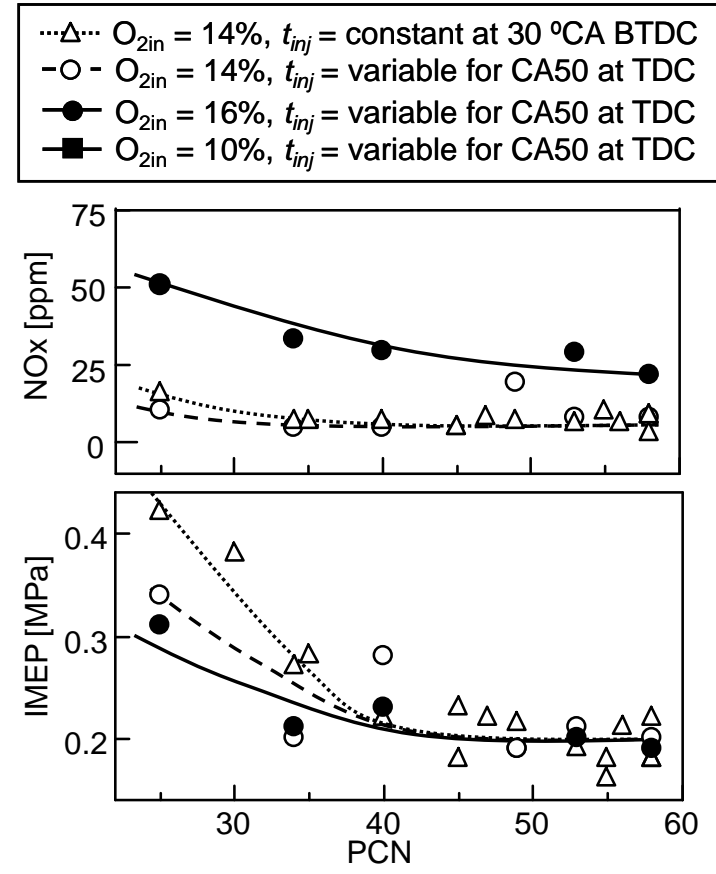

(a) Low load limit

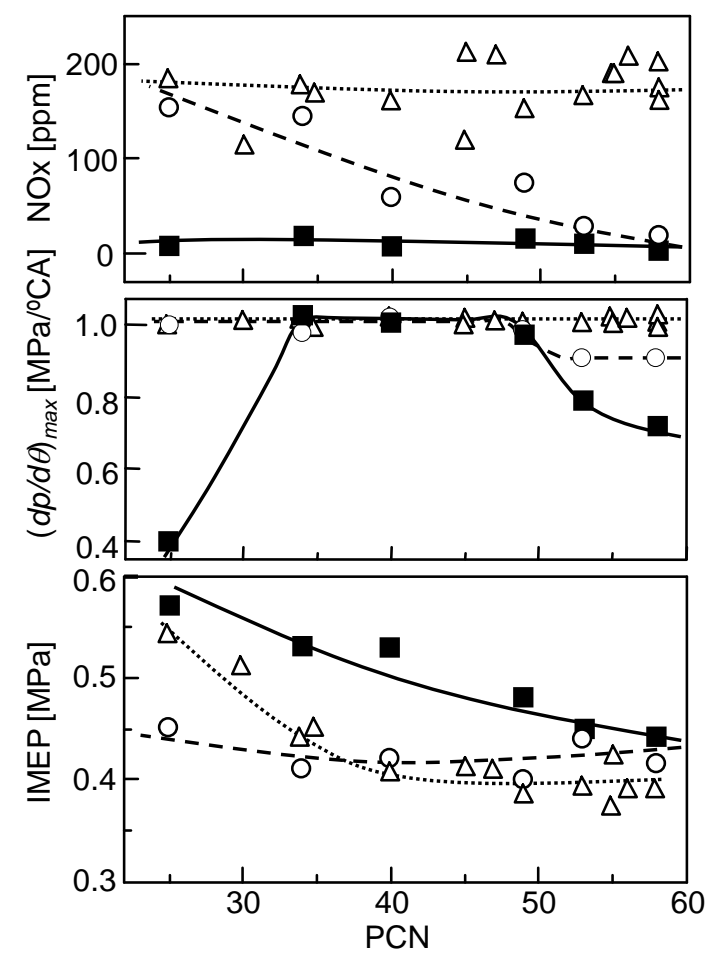

(b) High load limit

Fig. 10 Expansion of stable operating load range for smokeless, low-temperature combustion with holding combustion phasing at TDC and changing intake oxygen concentrations for various fuel ignitabilities (High load limit: $d p / d \theta_{\max }=1.0 \mathrm{MPa} /{ }^{\circ} \mathrm{CA}$, low load limit: $\left.\mathrm{COV}_{\mathrm{IMEP}}=5 \%\right)$. 


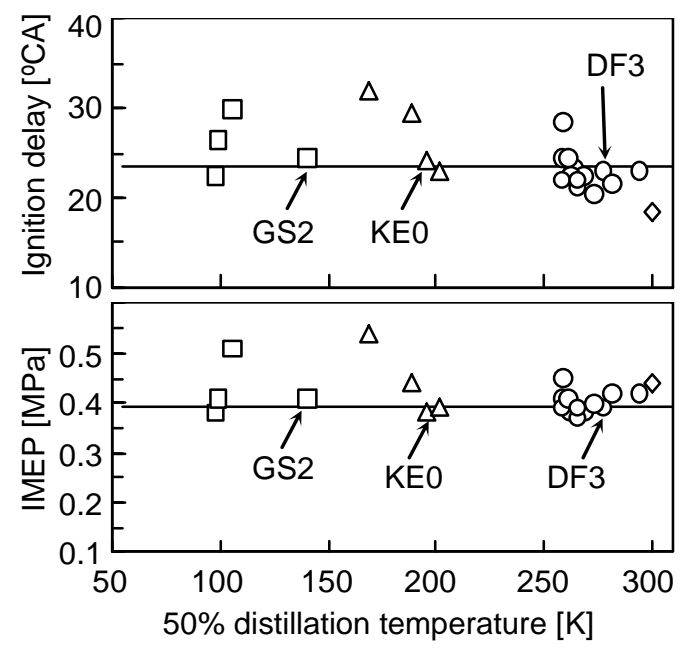

Fig. 11 Ignition delay and high load limit as a function of $50 \%$ distillation temperature $\left(t_{i n j}=30{ }^{\circ} \mathrm{CA} \mathrm{BTDC}, \mathrm{O}_{2 \text { in }}=\right.$ $14 \%)$. 


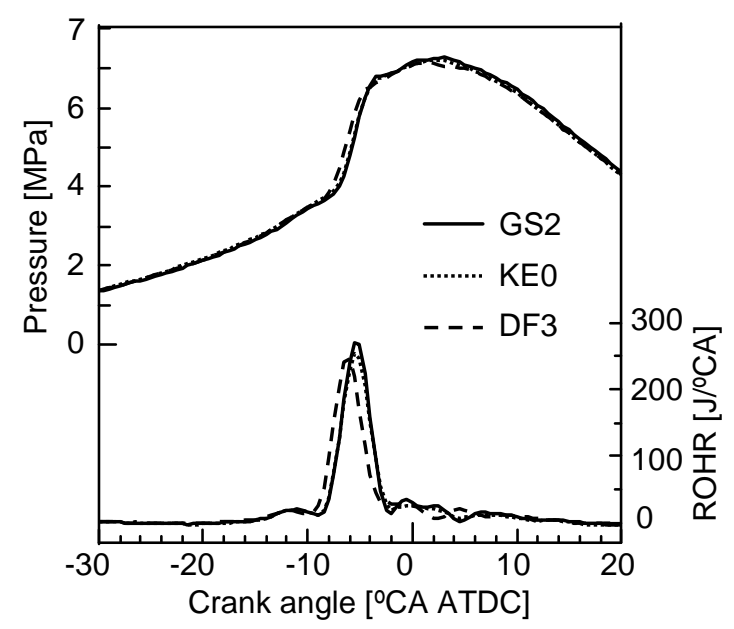

Fig. 12 Indicator diagrams for three fuels specified in Fig. 10. 


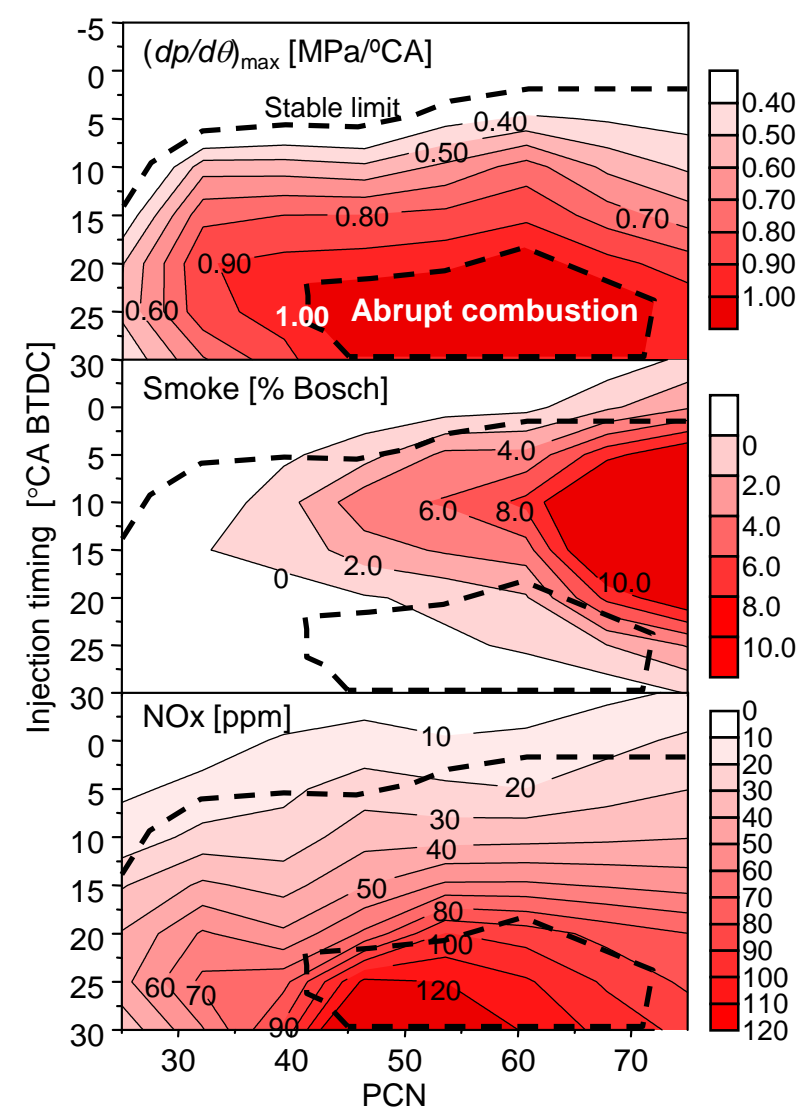

Fig. 13 Injection timing range for stable, low-emission, and low-noise operation as a function of PCN (IMEP $=0.4$ $\left.\mathrm{MPa}, \mathrm{O}_{2 \text { in }}=14 \%\right)$. 


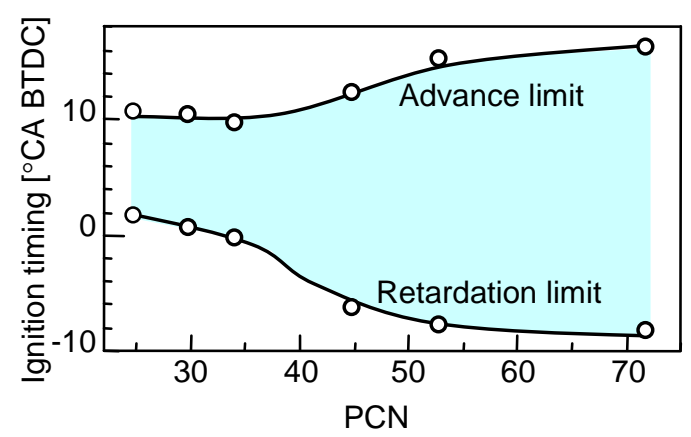

Fig. 14 Ignition range for advantageous stable, low-emission, and low-noise operation as a function of PCN (IMEP $=0.4 \mathrm{MPa}, \mathrm{O}_{2 \text { in }}=14 \%$ ). 